\title{
Pro Bono Legal Work: The disconnect between saying you'll do it and doing it
}

\section{Vinny Kennedy, Northumbria University, UK}

\section{Abstract:}

Pro bono is a significant component of one of the many professional obligations a lawyer has to fulfil for the public good. It is evident that this is acknowledged by not only those who practice law, but those who are training to be a lawyer and by the professional bodies. Despite this acknowledgement there is a clear disconnect between the importance placed on delivering pro bono services and the actual delivery of the same. There have been previous suggestions that in order to increase the commitment to pro bono work, there is a need to mandate its delivery. However, the notion of mandatory pro bono work has always been dismissed and therefore it is now appropriate to consider other ways in which a commitment could be encouraged and adopted.

This paper will consider the reasons why the profession, at all stages, considers pro bono to be such an important social function and whether such motivations are sufficient to sustain a commitment throughout a lawyer's career. Such considerations 
will be made from the perspective of a solicitor in England and Wales, as this is connected to the author's own pro bono experience. The paper will also consider why there is a disconnect, and what the rationale is for non-participation in pro bono work once in practice. It will consider the key barriers to full participation and recommend action that ought to be taken in order to develop a pro bono culture and therefore commitment.

\section{Key Words:}

Pro Bono

Solicitors

Professional Obligations

Public Service

\section{Introduction}

Pro bono is considered to be an important element of being a lawyer, it sets the profession apart from others and it is acknowledged that lawyers have a professional obligation to support and deliver pro bono services. It is understood that '... lawyers have reasonable moral duties to employ their specialised legal knowledge and skills to help people who need but lack access to the law'.$^{1}$ At a time where public funding

\footnotetext{
${ }^{1}$ Reed Elizabeth Loder, 'Tending the Generous Heart: Mandatory Pro Bono and Moral Development' (2001) 14 GJLE 459, 463
} 
is ever decreasing the importance that pro bono plays in providing access to justice is increasing. However, pro bono is not considered as a replacement to government funding and intervention, and rightly so. Currently pro bono work is delivered on a voluntary basis, ${ }^{2}$ in an ad hoc manner and it is unclear the extent to which such services are being delivered. What is clear is that throughout the various stages of legal practice, from student to retirement, there is an understanding that lawyers should provide pro bono services.

Despite this understanding, there seems to be a disconnect between the assertion of pro bono work as an important contribution to society that lawyers ought to provide, and the reality of such provision. It is suggested that if we continue to have a purely aspirational approach to pro bono obligations, as is currently the case, there will be insufficient participation as a result. ${ }^{3}$ Statistics demonstrate that commitment to pro bono work amongst the profession remains low. ${ }^{4}$ This paper will explore the tension between this disconnect. It will consider the motivations of higher education in exposing students to pro bono work, and the impact that this may have on the student's future commitment to such work. It will also highlight the approach taken

\footnotetext{
${ }^{2}$ It is considered as voluntary on the basis that there are no statutory requirements to undertake pro bono work, as there is in the US. However, it is noted that for some undergraduate law degrees students are required to undertake a clinical legal education module, which may incorporate pro bono work, and as such they are 'required' to undertake the same.

${ }^{3}$ Rima Sirota, 'Making CLE voluntary and Pro bono Mandatory: A Law Faculty Test Case' (2018) 78 L Law Rev 547-595, 567

${ }^{4}$ LawWorks, 'LawWorks Clinics Network Report April 2016 - March 2017' (Dec 2017) < https://www.lawworks.org.uk/sites/default/files/LawWorks\%20Clinics\%20Report\%202016-17.pdf $>$ date accessed 21 November 2018
} 
by the professional bodies, namely the Law Society of England \& Wales, suggesting that there is a significant push to encourage the profession to increase contributions. The paper will then consider the actual contribution by the profession, namely practising solicitors, and what barriers may exist that could prevent participation. Finally, it will provide recommendations of the steps that need to be taken in order to begin to address the disconnect. Such recommendations include widening the definition of pro bono so as to include the actual perceptions by the profession of what pro bono might entail; introduce a requirement of mandatory reporting of contributions to pro bono work by the profession; and to commence a cultural change in the view taken by the profession as a whole to pro bono work versus billable hours.

\section{The Impact of Defining Pro Bono}

It is commonly understood that pro bono publico means for the public good and by extension it is viewed as '... the provision of free legal advice for the public good'. ${ }^{5}$ The Joint Pro Bono Protocol for Legal Work (Joint Protocol) states that 'pro bono work means legal advice or representation provided by lawyers in the public interest, including ... [to those] ... who cannot afford to pay and where alternative means of funding are not available' ${ }^{6}$ This definition has been endorsed by the Law Society of

\footnotetext{
${ }^{5}$ Law Society of England \& Wales, The Pro Bono Charter (2017) 1

${ }^{6}$ Law Society, Pro Bono Manual A Practical Guide and Resource Kit for Solicitors (Nov 2016) 8
} 
England \& Wales, the Bar Council of England and the Chartered Institute of Legal Executives.

This definition appears to have been adopted by some of the larger firms operating within England \& Wales such as DLA Piper and Shoosmiths, who have incorporated the definition in the Joint Protocol within their own policies. ${ }^{7}$ However, research undertaken in 1998 suggested that there were various other interpretations of what pro bono could entail. Although this research was undertaken twenty years ago, and before the Joint Protocol was introduced, it could be argued that some of these alternative definitions are still prevalent today. Such alternative definitions include:

- '... the provision of free first interviews ...'

- '... charitable work ... even though this could cover non-legal activity, including fundraising for a local charity ...'

- For legal aid lawyers, pro bono also includes '... finishing legal aid cases for free when funding had run out or providing representation outside the scheme.' 8

In addition to having a variety of domestic definitions, there is also variation in definitions based upon jurisdiction. We are familiar with the mandatory requirements

\footnotetext{
${ }^{7}$ DLA Piper, Pro Bono Guidance $<$ www.dlapiperwin.com/export/sites/win/dowloads/WIN_Pro Bono Guidance.pdf $>$ date accessed 31 August 2018 and Shoosmiths, Pro Bono Policy Statement < www.shoosmiths.co.uk/about-us/pro-bono-policystatement-13361.aspx > date accessed 31 August 2018

${ }^{8}$ Lisa Webley, 'Pro Bono and Young Solicitors: Views from the Front Line' 3(2) LE 152-168, 154
} 
of pro bono activity in the US, and so in the American Bar Association's Model Rule 6.1 pro bono is defined as '... the provision of a minimum of 50 hours of legal services to persons of limited means ... contributions to law reform as well as voluntary financial contributions to organisations which support disadvantaged members of society ${ }^{9}{ }^{9}$ Within this requirement it is stated that an activity will not be considered as pro bono if a student has gained academic credit. In this instance it would largely decimate contributions to pro bono by students in England \& Wales where the opportunity to take part in pro bono activities are within a law school legal clinic, where pro bono is embedded into the curriculum and academic credit is awarded.

In light of the above, it is important to appreciate that despite the formalised definition in the Joint Protocol individuals will have their own interpretations. This has a significant impact upon the perception of the opportunities available to participate in pro bono activities once in practice. It may therefore be the case that a large proportion of the legal profession contribute their time to undertake pro bono work which is not formally recognised. Furthermore, the variations in definitions also make it difficult to compare between jurisdictions and so lessons learnt in a different jurisdiction is not directly applicable to any other. This is supported by Mcleay ${ }^{10}$ who suggests that it is difficult to compare the volume of pro bono work around the world because of the

\footnotetext{
${ }_{9}^{9}$ Alpheran Babacan and Hurriyet Babacan, 'Enhancing civic consciousness through student pro bono in legal education' (2017) 22(6) THE 672-689, 672-673

${ }^{10}$ Fiona Mcleay, 'The legal profession's beautiful myth: surveying the justifications for the lawyer's obligation to perform pro bono work' (2008) 15(3) IJLP 249-271, 251
} 
variations in definitions and the lack of consistent reporting of such work. Nevertheless, this paper will draw on experiences in the US and Australia for illustrative purposes.

\section{Professional Bodies Standpoint}

Tewksbury and Pedro state that '... what characterizes all pro bono legal work is a commitment and professional obligation to provide legal services for the betterment of society'. ${ }^{11}$ This is supported by the Law Society of England Wales who within their Pro Bono Policy (the Policy) state that pro bono work is an '... exceptionally important contribution to society ...' ${ }^{12}$ The provision of pro bono services is therefore considered to be a professional obligation, which is endorsed by the professional bodies in England and Wales. In particular, the Law Society have developed significant guidance to promote pro bono amongst the legal profession (namely solicitors). They have created The Pro Bono Charter (the Charter), they have contributed to the Pro Bono Joint Protocol on Legal Work and have implemented a Pro Bono Policy (the Policy). It is therefore clear that the professional bodies value and encourage individuals to undertake pro bono work.

\footnotetext{
${ }^{11}$ Richard Tewksbury and Elizabeth Pedro, 'Giving back and helping others: Pro bono legal work by young attorneys' (2000) 12(4) CJS 409-422, 410

${ }^{12}$ Law Society of England and Wales, Pro Bono Policy (undated) < https://www.lawsociety.org.uk/Supportservices/Practice-management/Pro-bono/Pro-bono-policy/ > date accessed 14 November 2018
} 
Within the Policy it states that the objectives of the Law Society ${ }^{13}$ in encouraging pro bono activities include: to promote the social contribution made by the profession; to improve access to justice and to meet unmet legal needs; to support solicitors to undertake pro bono work; and to strengthen existing networks to enable a collective response to the Legal Aid, Sentencing and Punishment of Offenders Act 2012. ${ }^{14}$ Under the Charter the Law Society recognises that '... at all stages throughout their career, solicitors have the capacity to use their professional expertise to help those with legal needs and [they] will strive to encourage a commitment to pro bono throughout the solicitor profession'. ${ }^{15}$ This commitment is reflected in the Joint Protocol, which highlights that 'commitment to the delivery of pro bono work is encouraged throughout a lawyer's professional life, as a student and in practice, through to and including retirement'. ${ }^{16}$ For this to be supported it is suggested that pro bono champions are required through all stages of the profession so as to ensure appropriate role models exist for the promotion of pro bono work. ${ }^{17}$

Although the guidance makes it clear that pro bono is not a replacement to legal aid, it does focus significantly on the commitment to improve access to justice, and to meet unmet legal need. Abbey and Boon go as far as to suggest that 'if government cannot

\footnotetext{
${ }^{13}$ Law Society of England and Wales. Thereafter any reference to the Law Society is that of the Law Society of England and Wales.

${ }^{14}$ Pro Bono Policy (n12)

${ }^{15}$ The Pro Bono Charter (n5)

${ }^{16}$ Joint Pro Bono Protocol for Legal Work < https://www.lawsociety.org.uk/Support-services/Practicemanagement/Pro-bono/The-pro-bono-protocol/ > date accessed 14 November 2018

${ }^{17}$ Loder (n1) 500
} 
or will not guarantee [access to justice], a profession which controls access has a social responsibility which it should not seek to evade.'18 There is therefore a tension between the professional bodies' objectives to promote pro bono work, which by extension includes access to justice, and the views of the profession, who become resentful of having to fill the justice gap that ought to be addressed by the government. Certainly in the US it has been argued that the professional bodies' approach to the delivery of pro bono work is aspirational, and as such actual participation remains low. ${ }^{19}$ That could apply to England \& Wales, particularly when consideration is made to the actual hours contributed to pro bono by the profession.

\section{The Attitude of the Profession}

Sossin suggests that 'if access to justice includes as one of its components access to lawyers, then it is appropriate to look to the legal profession for leadership in advancing access to justice in this sense' ${ }^{20}$ The profession does not appear to be in dispute with the premise that the provision of pro bono work is a professional obligation. This obligation is articulated by Hoffman, who confirms that 'Because access to legal services is important, and the position of lawyers is quite privileged, some conclude that the legal profession has an obligation to ensure that everyone has

\footnotetext{
${ }^{18}$ Robert Abbey and Andy Boon, 'The provision of free legal services by solicitors: a review of the report of the Law Society's Pro Bono Working Party’ (1995) 2 IJLP 261-280, 277

${ }^{19}$ Sirota (n3) 567

${ }^{20}$ Sossin referred to in Francesca Bartlett and Monica Taylor, 'Pro Bono Lawyering: personal motives and institutionalised practice' (2016) 19(2) LE 260-280, 267
} 
access to the legal system' ${ }^{21}$ The commonality in the arguments put forward for the justification for delivering pro bono work therefore seems to be that in order to facilitate access to justice, lawyers should make themselves accessible whether this be charging for their services, or providing it free of charge. This perception is perhaps as a result of the historical viewpoint of what a lawyer is and their standing in the community. Lawyers were once seen as serving for the public good and given their monopoly in providing legal services they are best placed to provide assistance where required. ${ }^{22}$ As a result of this privileged position, it is strongly felt amongst the profession that lawyers should not be allowed to escape this professional/ethical responsibility. ${ }^{23}$

However, it could be argued that the traditional concept of a lawyer is no longer applicable. It is questionable as to whether the practice of law is still considered as a profession, or whether it has transformed into a business. There has been an increase in the deregulation of lawyers, the Solicitors Regulation Authority (SRA) have shifted to an outcomes focused approach and the onus is very much on the individual to comply with their professional obligations. In addition, and more significantly, there has been an increase in the areas of law that is no longer considered to be a regulated activity, which requires supervision by the SRA. For example, there are licensed

\footnotetext{
${ }^{21}$ Elizabeth Hoffman, 'Legal education and early career mentoring: mid-career attorneys' pro bono commitment' (2007) 14(1) IJLP 81-96, 83

22 Mcleay (n10) 254

${ }^{23}$ Abbey \& Boon (n18) 277
} 
conveyancers; there has been an increase in will writing companies; and with the introduction of alternative business structures there are a number of companies that offer legal services (such as the Co-op). Further to this, there are an increasing number of in-house legal departments. ${ }^{24}$ Mcleay also highlights that ' $\ldots$ the heterogeneity of lawyers as a group and the shrinking of many of their associated monopolistic practices makes their pivotal role as the holders of keys to the justice system less secure ... ${ }^{\prime 25}$ To say that it is only the 'legal profession' that offer legal services is no longer the case, and therefore it raises the question of whether it should be the sole responsibility of the legal profession to provide access to justice in the way that has been identified above.

The notion of legal services being a business is also supported by academics and employers who emphasis commercial awareness as a key graduate attribute. Understanding how a law firm or barrister chambers work as a business is highly regarded by employers. This further contributes to the debate as to whether the profession should in fact be the sole provider of pro bono services. If operating purely as a business, it is clearly not a profitable activity to undertake work free of charge. When compared to other professions such as accountants, there are no equivalent obligations (although the argument regarding access to justice remains, for which there is perhaps no equivalent in many other professions). Some argue that 'the

\footnotetext{
${ }^{24}$ Abbey \& Boon (n18) 261-263

${ }^{25}$ Mcleay (n10) 263
} 
responsibility of ensuring access to justice [should rest] with government and that the profession's acceptance of an ethical responsibility to do pro bono may weaken the state's obligation to make adequate provision' ${ }^{26}$ However, others view pro bono work as enabling the individual to reconnect with the professional elements of the role of being a lawyer as a profession, rather than as a business. ${ }^{27}$

Irrespective of whether it is the sole responsibility of lawyers to provide pro bono services, many still consider it to be an important element of being a lawyer. It is acknowledged that there are many benefits to undertaking pro bono work, not only to the individual receiving the assistance, and the local community, but to the lawyer providing that service. Indeed '... pro bono legal work is seen as a valued and valuable component of a career by the majority of young lawyers' ${ }^{28}$ Rhodes 'describes many positive personal impacts that pro bono participation may have on lawyers, including alleviating depression and reviving sagging professional morale'. ${ }^{29}$ Davis also suggests that in addition to receiving emotional benefits from undertaking pro bono work, '... the experiences associated with doing pro bono work can re-shape their political attitudes'. ${ }^{30}$ The more cynical view is that undertaking pro bono work is for self-promotion, particularly by firms who wish to demonstrate their compliance with

\footnotetext{
${ }^{26}$ Abbey \& Boon (n18) 265

27 Mcleay (n10) 254

${ }^{28}$ Tewksbury \& Pedro (n11) 417

${ }^{29}$ Rhodes referred to in Martha Davis, 'Access and Justice: The Transformative Potential of Pro Bono Work' (2004) 73 F Law Review 903, 907

${ }^{30}$ Davis (n47) 908
} 
social responsibility. In particular criticisms suggest that firms undertake pro bono work in order to improve their image, to help retain high quality staff, and to recruit high achievers. ${ }^{31}$ Indeed it has been reported that firms use pro bono to market themselves to graduates, perhaps on the basis that they believe that graduates value the delivery of pro bono work. However, within the job description and attributes, a commitment to pro bono is not a criteria, inferring that employers are not concerned as to whether or not a candidate is in fact committed to pro bono work. ${ }^{32}$

Many law firms do, however, see the benefit of their staff undertaking pro bono activities. In Australia, it has been suggested that the increase in the number of much larger firms has shifted the obligation from the individual to the firm. ${ }^{33}$ This shift in responsibility can be seen in England \& Wales, where the top 10 firms $^{34}$ have dedicated pro bono initiatives and have integrated pro bono work within their day-to-day activities. However, it is also the case that although participation in pro bono work may be increasing and becoming more widespread, the actual time spent delivering pro bono work is relatively low. ${ }^{35}$ McKeown argues that '... at a time when demand, or at least a need, for pro bono legal services is increasing, the percentage of solicitors

\footnotetext{
${ }^{31}$ Mcleay (n10) 251

32 Linden Thomas, 'It Puts the Law They've Learnt in Theory into Practice: Exploring Employer Understandings of Clinical Legal Education' in L Thomas, S Vaughan, B Malkani and T Lynch (eds), Reimagining Clinical Legal Education (Hart 2018) 138

33 Mcleay (n10) 250

${ }^{34}$ According to The Lawyer UK 2002017 and based on annual turnover < https://www.prospects.ac.uk/jobsand-work-experience/job-sectors/law-sector/top-uk-law-firms > date accessed 21 November 2018

${ }^{35}$ Mcleay (n10) 251
} 
providing such services is decreasing' ${ }^{\prime}{ }^{36}$ There are some stark statistics that reveal the actual, reported, contribution to pro bono work by the profession. Webley identified that 'Twenty-seven percent ... of the pro bono active profession carried out less than 2 hours' pro bono work a month ... ${ }^{37}$ In their 2016-2017 report LawWorks confirmed that 'Last year 6,000 individuals volunteered across the LawWorks Clinics Network, a $24 \%$ increase on the previous year'. ${ }^{\prime 8}$ This may be so, but given that there are currently 146,625 practising solicitors in England \& Wales, ${ }^{39}$ that only represents approximately $5 \%$ of the population of practising solicitors. It should perhaps be noted that these statistics are reflective of activities that are reported, and based on an earlier discussion, not all pro bono work is therefore being reported. Nevertheless, it does demonstrate a disconnect between the importance of pro bono work advocated by the profession, and the commitment given to pro bono work.

If students value undertaking pro bono work within their undergraduate degree (discussed below); if the professional bodies encourage individuals to participate throughout their legal career; and if employers say they believe it to be a professional obligation why is there a lack of commitment from qualified solicitors? Reasons cited for not undertaking pro bono work whilst in practice include: lack of

\footnotetext{
${ }^{36}$ Paul McKeown, 'Pro Bono: What's in it for law students? The students' perspective' (2017 24(2) IJCLE 43-80, 47

37 Webley (n8) 159

38 LawWorks (n4)

${ }^{39}$ Solicitors Regulation Authority < https://www.sra.org.uk/sra/how-wework/reports/data/population solicitors.page $>$ date accessed 21 November 2018
} 
experience/knowledge in the law, lack of time, limitations imposed by regulation, and not being aware of the opportunities available. ${ }^{40}$ It is the case that regulations may restrict, even prevent, participation. In particular the Joint Protocol states the following:

2.5 The pro bono legal work should only be undertaken by a lawyer who is adequately trained, has appropriate knowledge, skills and experience and, where necessary, is adequately supervised for the work in question.

$2.6 \ldots$ minimum level of legal expertise and experience as would be required if that particular work in question was paid for.

2.9 Pro bono legal work must not be undertaken without appropriate insurance.

Whilst it is clear that these measures are required to protect the client/consumer, it is also understandable that they can form a barrier to participation by lawyers who lack support from their firm to undertake such work. Those in this position often dedicate their personal time and funds to providing pro bono services, and are aware that such dedication will not be rewarded by their employer. ${ }^{41}$ Therefore, to dedicate additional

\footnotetext{
${ }^{40}$ These appear to be the overriding reasons for lack of participation, which have been identified in numerous studies including McKeown (n16) 45 and Tewksbury \& Pedro (n29) 417

${ }^{41}$ Webley (n8) 277-278
} 
hours outside of the standard contractual obligations requires a significant commitment. Therefore, the lack of participation in pro bono work can be attributed to the prioritisation afforded by the employer to such work. ${ }^{42}$ This is highlighted by Bartlett \& Taylor who identified that although 'Our junior respondents were ... inculcated with the spirit of pro bono, they knew they must carefully manage their hours with an eye to the corporate imperatives of their employers' ${ }^{43}$

There seems to be a general sense that pro bono work is not valued as the equivalent to billable hours, and although the profession considers pro bono work to be important, yet again it does not appear to reflect the reality. It is suggested that in order to increase a commitment to pro bono work by practising solicitors, firms need to be willing to '... view pro bono as a partnership between themselves and their staff, if they allow them time, provide them with supervisory support and offer sufficient recognition for their efforts'. ${ }^{44}$ This viewpoint is reflected in a response within the study undertaken by Bartlett \& Taylor, where a respondent commented as follows:

I think the bottom line is, it has to be work which has a value, that people aren't being punished for doing, and by that I mean if you're in a firm and the structure in the way in which lawyers are assessed is they write down things

\footnotetext{
42 Tewksbury \& Pedro (n11) 147

${ }^{43}$ Bartlett \& Taylor (n20) 276

${ }^{44}$ Webley (n8) 168
} 
on a time sheet, pro bono has to be part of that, it's got to be treated as real work ... it's got to be actually seen as being part of someone's day to day practice as opposed to some special added extra that you're meant to do when all the other work is finished. ${ }^{45}$

This would potentially be difficult for small-medium sized firms whose profit margin is prioritised. As identified earlier, the current top 10 firms in England \& Wales are already integrating pro bono within the day to day activities of their solicitors. However, the opportunity or ability to undertake pro bono work is dependent on the ethos and commitment of the firm itself. Where there is a '... non-existent programme or the [lack of a] time recording system [it] meant pro bono work was hard to undertake and was not encouraged by the employer'. ${ }^{46}$ Furthermore, Webley argues that 'High street practitioners were more likely to receive a strong signal from their firm, either being encouraged to carry out pro bono legal services ... or discouraged from doing so $\ldots{ }^{47}$ Despite the barriers placed on practitioners there is a sense that given the opportunity to do so solicitors do want to take part in pro bono work. ${ }^{48}$ There is therefore scope to increase and develop commitment to pro bono work that is reflective of the importance placed on undertaking the same.

\footnotetext{
${ }^{45}$ Bartlett \& Taylor (n20) 274

${ }^{46}$ Bartlett \& Taylor (n20) 277

47 Webley (n8) 157

${ }^{48}$ Tewksbury \& Pedro (n11) 419
} 


\section{Legal Education and Pro Bono}

If there is scope to develop a pro bono commitment, this may well need to start at the beginning of an individual's legal career. It is therefore prudent to ascertain whether such a commitment could be taught, or inculcated within an undergraduate law degree.

\section{Contribution by Law Schools}

Higher Education institutions often place great emphasis on the provision of clinical legal education (CLE) within which pro bono is featured. There is an argument suggesting that there is a distinction between CLE and pro bono work, whereby the former is embedded into the curriculum and focuses on the development of skills and the teaching of professional obligations. ${ }^{49}$ Although the intricacies of defining CLE and pro bono is beyond the scope of this paper, it is acknowledged that differences in definitions generally exist. Nevertheless, there are some overlaps between CLE and pro bono activities offered in law schools, and so this paper will consider, in the more general sense, students providing a legal service free of charge to the general public.

${ }^{49}$ Babacan (n9) 676 
Grimes and Musgrove suggest that pro bono enables students to '... develop their commitment to, and understanding of, professional values, which should in turn lead to their active involvement in pro bono work later in their professional lives'. ${ }^{50}$ Participation in such activities is multi-faceted. Not only does it provide students with an opportunity to enhance their employability skills but also enables them to contribute to access to justice through the provision of legal services. It is the first stage to legal training and therefore it also introduces professional practice to students, allowing them to 'try before they buy'. Dignan and others identify the increase in the number of law schools offering students pro bono and clinical work within the undergraduate law degree, confirming that in 2014 'over $70 \%$ of UK-based law schools have clinics' ${ }^{51}$ There is therefore great potential for the desired outcome, referred to above, to be realised. There is plenty of opportunity for law students to be exposed to the harsh realities of life and to appreciate the struggles experienced by others when trying to access the law. As such, there are numerous opportunities for students to develop altruism, which they can continue to develop in their professional careers, and which motivates them to continue to participate in pro bono work.

However, this idealistic impact of pro bono work upon an undergraduate student is perhaps unrealistic. Not only are law schools motivated to provide these

\footnotetext{
${ }^{50}$ Grimes and Musgrove quoted in Babacan (n9) 673

${ }^{51}$ Frank Dignan, Richard Grimes and Rebecca Parker, 'Pro Bono and Clinical Work in Law Schools: Summary and Analysis' (2017) 4(1) AJLE 1-16, 1
} 
opportunities for reasons of access to justice, but also for reasons of '.. the consumerization of legal education, the employability (or otherwise) of graduates entering a competitive job market and, possibly, an increasing recognition that effective learning requires an active engagement by students in the educational process'. ${ }^{52}$ These factors impact upon the provision of pro bono work, which could either be voluntary or compulsory (as an academic credit bearing module); it could be ad hoc depending on the demands of the local community, or sustained as part of a student legal clinic; and it could be focused on social justice or simply exposing students to legal work experience. The conclusions drawn by Babacan and Babacan in 2017 was that '... unstructured experiences in student pro bono is not likely to result in the social transformation necessary to instil a commitment to providing access to justice and service to disadvantaged groups following graduation'.53 McKeown further argues that having pro bono in a legal clinic as an assessed component of a degree leads to extrinsic motivation and as such it will not lead to an inherent desire to continue to undertake pro bono work once the 'reward' of the grade has been given. ${ }^{54}$ The ideal also relies on academics, who are potentially seen as mentors, actively encouraging students to build a pro bono ethic. For this to occur there are several assumptions that have to be made, including; that the academic is/was a practitioner, that they actively take part in pro bono activities themselves and that

\footnotetext{
52 Dignan (n51) 1

53 Babacan (n9) 673

54 McKeown (n36) 51
} 
whilst in practice they had a positive experience of pro bono work. If this is present, students could potentially mirror this behaviour and develop a pro bono ethic to take forward to their professional lives. Hoffman suggests that 'Having a group of teachers and/or mentors who confirm the importance of pro bono might be critical in attorney's continued commitment to pro bono work'.55 Therefore, although law schools appreciate the importance of pro bono work, beyond graduation, there are no incentives for a law school to ensure that a student continues to undertake pro bono work.

\section{$\underline{\text { Student Motivations }}$}

There have been several studies that consider student motivations in undertaking pro bono work. ${ }^{56}$ In a study conducted by Rhodes, and cited by McKeown, 'Only 31\% of the respondents indicated a desire to promote social justice..$^{\prime 57}$ as being a reason for undertaking the same. In McKeown's study, it was reported that 'respondents ... valued the skills development and enhanced employment prospects rather than the altruistic benefits of carrying out such work' ${ }^{58}$ This therefore suggests that students are motivated by personal gain, and view their pro bono experiences at undergraduate level as a form of work experience. Given the current job market, it is understandable

\footnotetext{
${ }^{55}$ Hoffman (n21) 85

${ }^{56}$ An example of which is Paul McKeown, 'Law student attitudes towards pro bono and voluntary work: The experience at Northumbria University’ (2015) 22(1) IJCLE 22

57 McKeown (n36) 11

58 McKeown (n36) 22
} 
that students want to ensure that they provide themselves the best opportunity to gain employment once they have graduated. This, in part, is ensuring that they have the requisite skills to be 'job ready', something which employers have expressed concerns about. Hoffman argues that although law schools encourage students to appreciate pro bono work '... law students hear not only the words within the classroom, but also the external pressures of the job market, their student debt, and the stress of billable hour minimums'. ${ }^{59}$ This is understandable, however, it does little to contribute to a commitment to pro bono work.

In essence, a student may undertake pro bono work for practical reasons, whereby they wish to develop their skills and enhance employability. Alternatively, they can be motivated by tactical reasons, where they see the benefit of promoting the image of lawyers and the institution that they attend; or for ethical reasons where they feel that it is the profession's moral obligation to provide such services. ${ }^{60}$ The latter is somewhat reflective of the profession's attitude towards pro bono work, as previously discussed. Despite these differing motivating factors, it is also the case that students do appreciate the importance of pro bono work within the profession and the need to provide a public service. ${ }^{61}$ Yet again, the importance of pro bono is emphasised, but research (as highlighted) suggests that the number of individuals that are committed

\footnotetext{
${ }^{59}$ Hoffman (n21) 84

60 McKeown (n36) 49

${ }^{61}$ McKeown (n36) 58-60
} 
to pro bono on a long-term basis is low. It is perhaps limited to those that had entered Higher Education with a desire to undertake such work, or to those who '... originally become exposed to pro bono work because it is mandated, or they wish to achieve a good grade, [where pro bono is embedded within the curriculum, who] ... may then experience the intrinsic value of the work itself thus shifting their own values', ${ }^{62}$ which supports continuation of pro bono work once qualified. In a study conducted by Bartlett and Taylor, ${ }^{63}$ a respondent suggested that their motivation to undertake pro bono work once in practice stemmed from the fact that rather than having to pay tuition fees, they had received a grant. On this basis, they felt that as society had paid for their education, it was appropriate for them to give back to society by providing pro bono services. Presumably, the introduction of tuition fees will have had an impact on students perception of what they feel they owe society, or what society owes to them.

Student attitudes to pro bono work can be demonstrated from the reflections of students in the Birmingham Law School Pro Bono Group (the Group). ${ }^{64}$ Following activities undertaken in the 2017 National Pro Bono Week four students reflected on their involvement within the Group and the activities they had been involved in. They commented upon the practical legal experience that pro bono work provides to

\footnotetext{
62 McKeown (n36) 53

63 Bartlett \& Taylor (n20) 270-271

${ }^{64}$ Gurpreet Ballagun, Emerald Hutton, Jasmine Lalli and Catherine Ruta, Reflections on participation in the Birmingham Law School Pro Bono Group (2017) < http://epapers.bham.ac.uk/3068/ > date accessed 14 November 2018
} 
students. They also identified that pro bono work enables them to network with the profession, presumably for future employability purposes, and that they could learn and develop their skillset further. However, they also recognised that their involvement in the Group contributed positively to the local community who had nowhere else to access such assistance. Although they were able to identify the positive impact of pro bono work, whether their involvement in the Group instilled a long-term commitment to pro bono work is open to question. Nevertheless, students who undertake pro bono work as part of their undergraduate law degree often comment upon their experiences positively, and those students tend to express ' ... a stronger opinion that students should undertake pro bono work as a mandatory part of their programme of study ...' ${ }^{65}$ Mandating pro bono work at undergraduate level may not have the desired effect of instilling a long term commitment to pro bono. Loder ${ }^{66}$ suggests that students who have a predisposition to pro bono work will not be adversely affected if they are required to do pro bono work on a mandatory basis. However, where a student did not have this pre-existing desire to do pro bono work, they are more likely to feel resentment towards such work, which can have a negative effect on building a pro bono culture and/or long-term commitment.

Thus, at the legal education stage emphasis is placed on the importance of pro bono work as a means to develop a student's understanding of the law and professional

\footnotetext{
65 McKeown (n56) 29

${ }^{66}$ Loder (n1) 475-476
} 
practice. The positive by-product of this is the contribution made to access to justice to the local community upon which the law school serves. It is not in dispute that law schools and law students value the importance of pro bono work, identifying it as a professional obligation. However, as has been demonstrated above, beyond graduation there is a lack of a consistent and systematic approach to actively encourage students to commit to pro bono work on a long-term basis.

\section{Recommendations for Developing a Pro Bono Commitment}

As has been identified the significance of undertaking pro bono work is understood throughout a lawyer's career, as a student through to retirement and is both supported and encouraged by the professional bodies. The reality is that there are lawyers who dedicate a considerable amount of time and effort to delivering pro bono services, whether this be for personal, professional or ethical reasons. Such efforts should be commended as an '... exceptionally important contribution to society' ${ }^{67}$

The de-regulation of the profession has brought into question where the responsibility for providing pro bono services should lie. In particular, the question is whether it should be the sole responsibility of lawyers. Irrespective of this, it is acknowledged that those who do provide legal services are in a privileged position, as specialist

67 Pro Bono Policy (n12) 
training enables them to negotiate complex legal rules which the general populace would be unable to successfully do without assistance. In light of this, it is perhaps fair to suggest that if lawyers hold the key, they should be prepared to use it to let others through the door.

The concern therefore is not whether the profession considers pro bono an important social function, but the level of commitment and dedication shown by the majority of practising solicitors. Looking to the LawWorks statistics from their 2016-2017 report, less than $5 \%$ of solicitors with a practising certificate were noted as having volunteered in that year, whilst in that same year the number of enquiries to clinics within the network were 58,511 . This would seem to be disproportionate ${ }^{68}$ and not reflective of the significance placed on the role of pro bono in society. It is perhaps also not reflective of people's desire to undertake pro bono work but for the perceived lack of opportunities available.

It is argued that there is an abundance of opportunities, but this is highly dependent on the definition of pro bono that is being used. The first recommendation would therefore be to re-define pro bono, or at least widen the scope. The definition in the section above highlights that it is essentially the provision of free legal advice or representation for which the lawyer is not receiving payment in exchange. Some of

${ }^{68}$ LawWorks (n4) 
the alternative definitions identified would clearly fall within this definition, the provision of a free first interview with a client is the provision of legal advice, for which the lawyer receives no payment for. It is appreciated that the intention is for the client to subsequently instruct the lawyer, however, this is not guaranteed and the time spent discussing the matter and providing limited advice still falls within the definition of pro bono (albeit might not be directed at someone who cannot afford to pay). In addition, representing a client outside the scope of a legal aid certificate, is still the provision of legal representation for which no payment is made for the services, and again, clearly also falls within the definition. The research undertaken to obtain these alternative definitions was conducted some twenty years ago, and it is perhaps important to ascertain what the profession currently considers to be the provision of free legal advice and representation. A dialogue needs to be opened with the profession so that the definition can be widened, and the opportunities made clear to those who perhaps already undertake pro bono work.

Once an expanded definition has been established it would be appropriate to formally record the activities undertaken, which demographic undertake such activities and the number of hours delivered. It would then be possible to draw conclusions on the balance between what is said, and what is done. A clear picture could then be formed as to whether the profession are delivering the services that they profess to be of such importance and significance in society. Previous studies have attempted to record these issues so that such conclusions can be drawn. However, given that there are 
currently 146,625 practising solicitors a larger scale study would be in order. The second recommendation would therefore be that there should be mandatory reporting of pro bono activities. Even if the return is nil, it reminds the individual of their professional obligations and the professional bodies desire to encourage and promote pro bono activities. The practicalities of mandatory reporting would require some thought. At the time of renewing a practising certificate, the solicitor needs to confirm that they have completed their reflection of practice and undertaken all relevant activities to ensure they remain abreast of current practices. Therefore, it is possible that at that time of renewal a tick box exercise could be completed for the type of pro bono activity that the solicitor has been involved with, with a corresponding number of hours recorded, even if this is nil. The results can then be published by the SRA alongside their regulation population statistics.

Although lack of opportunities is cited as a reason for not undertaking pro bono work, of significant impact on the individual's commitment is the attitude to pro bono work by their employer. Employers need to send a clear message that pro bono is morally and professionally valued and that firms will not only support but also encourage their solicitors to participate. ${ }^{69}$ The third and final recommendation, which is aspirational, is that there needs to be a cultural change within the profession of how pro bono is viewed by the majority. There is a need for firms (not just individuals) to

\footnotetext{
${ }^{69}$ Hoffman (n21) 93
} 
show a commitment to pro bono work, which they regard as an important part of being a lawyer. This would therefore require pro bono hours to be considered as worthy as billable hours, with their own targets and contributing to career progression. Firms need to demonstrate their willingness to make a positive contribution to society and act as role models for their employees to emulate. In the current economic climate, where profit margins and sustainability are key concerns for firms (particularly the smaller firms) it may be difficult to effect such a cultural change. Therefore, having gone full circle, we need to look to students to carry the flag for pro bono work. Although students cannot be taught altruism, undertaking pro bono work within an undergraduate degree can have an impact upon them, particularly where they are taught and supervised by pro bono champions. Momentum is needed throughout the lawyer's career for such a commitment to be sustainable. 